\title{
1. Introduction: from time to timespace and forward to time again in migration studies
}

\section{Ben Page, Anastasia Christou and Elizabeth Mavroudi}

\section{FROM TIME TO TIMESPACE}

When thinking about time and migration there is a rich vein of aphorisms to mine. How about this line from Tennessee Williams' 1945 play The Glass Menagerie? 'I didn't go to the moon, I went much further - for time is the longest distance between two places.' It seems an apt quotation given the goal of this book is to critically assess the value of analysing international migration through a framework of time, space and timespace. But Williams' words are helpful not only because of the elegant, provoking way they muddle up the temporal and the spatial, but also because some of the themes of the play are so relevant to the field of migration studies: the power of memory, the difficulty of disconnecting from existing social worlds, the robustness of fragile dreams. Tom, the character who says the line, is reflecting in his old age on his mother's attempts to use emotional ties to prevent him from leaving home when he was young. But he did leave and he never went back.

Several of the chapters in this book tell stories of the mobility of youth, of relations across generations, of return migration, of the life course; but in each case it is axiomatic that you can never really 'go back' - you can only 'go on'. There is too much change in the world to ever return to the same place: you have changed, the other people in your life have changed, your social relations have changed, the places you left have changed. Sometimes those places are changed precisely by people who move away. Memory may provide something to hold on to, but the giddying flow of time reveals that the fixity suggested by precise 
geographical co-ordinates is a bit of an illusion. The drive to move, to search for something better, to escape seems to be a powerful human force.

Yet, some of the chapters in this book also speak to a powerful countervailing force: the drive to fix people where they are assumed to belong, or indeed to keep them away from where they are perceived not to belong (through border controls and deportation for example). This drive towards stasis extends to the idea of human subjectivity too, through the ambition to fix, finish or complete the individual human subject. Most people in the world still don't migrate very far. Stubbornly, only around 3 per cent of the world's population are 'international migrants'. Analysis of the geography of family names over decades of UK censuses reveals an extraordinary story of immobility and stasis (Cheshire and Longley, 2012), even though historians now understand this era in terms of dramatic shifts in the structure of the British economy. The project of building 'home' in specific locations often means that many places feel slow to change. Many people use pictures drawn from memory to work hard to try to prevent places from changing in the future. Ideas about these two opposing forces (mobility and stasis) are the motors that animate and complicate the field of migration studies; but whilst they are often understood in spatial terms, their temporal dimensions are less often considered.

Most of the chapters in this book began life as presentations at the Royal Geographical Society with the Institute of British Geographers (RGS-IBG) conference at the University of Exeter in 2015. The immediate prompt for those conference sessions was Melanie Griffiths, Ali Rogers and Bridget Anderson's 2013 paper 'Migration, Time and Temporalities: Review and Prospect', which starts from the observation that migration has generally been viewed as a spatial process and the temporal dimension was largely left implicit. They echoed Saulo Cwerner's 2001 call that migration research needed to think harder about time and temporality. This was a sentiment that immediately felt true to us too. Responding to this injunction was not merely an exercise in academic 'tidying up' by filling a gap - rather, attention to temporality is of particular value as it allows researchers to develop new insights into migrants' understandings of their own experiences (Bastia and McGrath, 2011, p. 32).

There have been various exceptions to the generalization that time is under-analysed in migration studies. These come both in the form of some specific, influential pieces of research in the recent past about the temporalities of migration that Griffiths et al. identified (Bastia and McGrath, 2011; Cwerner, 2004; Gardner, 2009; King et al., 2006; 
Maclean, 2003; Peeren, 2006; Potter and Phillips, 2008; Westin, 1998) and in the form of some temporal concepts that were well established within the field (life course, generation, journey-times). Furthermore, the lack of any recognition of the legacy of the work on time and migration by the Swedish geographer Torsten Hägerstrand is, we feel, an omission from the call to insert time into migration studies - one that we are glad to have rectified a little in Jørgen Carling's contribution to this volume (see also Gren, 2001). In addition, we would add that for those working with a methodology that prioritizes quantitative data, the temporal dimensions of migration expressed in a straightforward linear sense through time-series data were also always important. But, despite these caveats, the idea that time is under-analysed in migration studies remains salient.

Following Griffiths et al.'s working paper, several of the authors who have contributed to this volume had already started to explore the temporal dimensions of migration elsewhere. Melanie Griffiths (2014) developed a typology of temporalities (sticky, suspended, frenzied and ruptured) to think about the variable experiences of failed asylum seekers. Jennifer McGarrigle (2016) has shown how using temporality to study migrants' residential settlement patterns in Lisbon can refresh hackneyed accounts of choice and constraint. Perhaps the most conceptually ambitious engagement with these debates has come from Francis Collins and Sergei Shubin, who have drawn on Heidegger to explore the experience of 'being on the move', starting from the claim that time is not a linear sequence that measures and regulates life (Collins and Shubin, 2015; Shubin, 2015). Rather, from this perspective, time is multiple and different senses of future, present and past co-exist and interact simultaneously, just as a migrant's long-term conscious plans co-exist with their immediate moods and reactions. The authors argued that a migrant's subjective engagement with time happens through the affective condition that Heidegger called attunement (Stimmung), which shapes 'what individuals can do and reflects how they encounter others' (Collins and Shubin, 2015, p. 97). So time, they argue, can be understood through the subjective experience of migrants without insisting on the primacy of human agency. They use this framework to critique the existing way that migration scholars make assumptions about the direction and rhythm (transitions) of the life course and about the capacity of migrants to manage time as a tool for meeting certain plans.

Other researchers in the field have taken 'time' in different directions, focusing on: how temporal boundaries work both as a disciplinary practice of the state and as a tool of identity-building for temporary student-workers and tourist-workers in Australia (Robertson, 2014, 
2016); the relationship between the present and the future in young Peruvians' aspirations for migration (Crivello, 2015); and an Iranian migrant mother's conscious disturbance of singular, linear time in her photo albums by weaving family pasts into the post-migration present and subsuming her own milestones within a more circular family time (Pitt, 2015). From the precarity of transient hotel workers (Underthun, 2015) to the construction of the religious migrant self (Wong, 2014), temporality is emerging as a key theme in current thinking about migration.

However, despite our initial intentions, our discussions when the papers were first presented took us away from a focus on 'time' by shifting the conceptual register to the idea of 'timespace'. Conceptually we migrated from time to timespace as the pre-eminent conceptual lens through which to view the assembled empirical materials. The concept of timespace emerged from the discipline of geography at a very specific moment around the Millennium - it was primarily a reaction to the 'spatial turn' that had been occurring across the wider domain of social and cultural theory in the 1980s and 1990s. The idea of timespace was to challenge "the formulations of space evident within the spatial turn ... which, at root, seem premised upon a familiar and unhelpful dualism moving around the foundational categories of Space and Time' (May and Thrift, 2001, p. 1). Building on work by Doreen Massey (1994), the idea was to move away from oscillating between giving priority to time at one moment and to space at another, and instead recognizing their interdigitation. Secondarily, the emergence of timespace was also a reaction to attempts in the 1990s to develop a social theory of time, which (as with the spatial turn) was also premised on the possibility of treating time and space in isolation. The key arguments developed by Massey, May and Thrift were successfully visualized in the amalgam of timespace, with its assertion that it is only by compounding the two terms that it is possible to start thinking about the multiplicity of space-times.

The original collection of essays that popularized the term 'timespace' covered a great deal of empirical terrain, but not explicitly human mobility or migration (May and Thrift, 2001). The intention of this current book then, was to take some of the questions and framings from that set of discussions and apply it to a new empirical field (migration studies). Specifically, we set out to pick up May and Thrift's four 'domains' of timespace (the rhythms of the global environment, the temporal effects of systems of social discipline, time-related technologies and, finally, texts about time) and think through how they provided a framework for analysing international migration. These four domains generate 'a radical unevenness in the nature and quality of social time 
itself, with this spatial variation a constitutive part rather than an added dimension of the multiplicity and heterogeneity of social time or ... TimeSpace' (2001, p. 5). In other words, it is through these domains that the heterogeneity of the social character and experience of time is constructed.

This fourfold conceptual framework needs some further explanation. First, the global environment provides a series of timetables through which times is shaped (such as diurnal cycles, menstrual cycles, seasons). That such timetables have more significance to some social groups (women, shift-workers, farmers) within any culture, and more significance to some cultures than others, contests any claim that there is a universal experience of the rhythms of the global environment. The second domain in which a particular sense of time comes into being is pinpointed by looking for ways in which people's time is socially disciplined in particular spatial settings (the factory, the home, the school, the office). Contrasts between 'time for family' and 'time for work' are constructed as a result. Again, the experience of the social systems that bring discipline to time is different in different locations, and changes through history. Further, this second domain demands an analytical engagement with the tradition of thinking through the character of power (authority, coercion, networks, self-discipline, and so on) in order to assess the means and extent by which these forms of social discipline occur. The third domain focuses on the role played by specific technologies in shaping our experience of time (sun-dials, clocks, virtual reality). Power is significant here too in so far as it shapes not only access to devices and instruments, but also the purposes to which these technologies are put. The factory clock and the technology of 'clocking on' would be a clear example of how these devices work in the interests of particular social groups in some places at some times.

The fourth domain brings together the written texts that explicitly address the idea of time. This domain focuses on the role played by specific texts that are both about time and have the effect of shaping our everyday experience of time. These texts are our conscious attempts to understand the consequences of new social constructions of time. The goal of these texts is to articulate the social meanings of these changing experiences of time; and here too critical analysis takes us into the domain of the politics of representation, and ideology/discourse. However it is also important to note in relation to the fourth domain that, as May and Thrift put it, 'the manner in which we conceptualize TimeSpace has import for the way in which we come to act in TimeSpace' (p. 6). That is to say that we should not draw an overly strong distinction between the way we think about the construction of timespace and the 
way we construct timespace through the material practices of everyday life. So this fourth domain is firmly within the overall schema rather than separate from it. Indeed, though these four domains are distinct, May and Thrift are at pains to point out that they cannot be understood in isolation, but provide an inter-related site in which timespace is made, remade, lived, experienced, imagined and thought about. For us these domains produce a central question: how, when and where do natural timetables, social systems of temporal discipline, technologies and texts matter in the way that time is constructed, experienced and critically interpreted in international migration studies?

\section{TIME AFTER TIMESPACE}

The concept of timespace was, as explained above, very much one that emerged at a particular moment within Anglophone social science. It is still of great value, but that moment has passed. If the ways in which we experience ideas are dynamic then so too is the practice of critical analysis. Fifteen years on from those discussions we cannot imagine that the analytical framework outlined above makes quite the same sense now as it did then - even when applied to a new empirical object (international migration). Another question emerges as a result: how do we think about the social experience of time and space after we have internalized the idea of timespace?

Any account of time undertaken now would have to consider the critique of the dualistic separation of time and space embedded in the notion of timespace. However, in a way, the central lesson of that critique has been learned. It has become axiomatic both to think (and write) of time and space together, and also to think (and write) of the compound as multiple and heterogeneous. We are habituated into looking for the spatial objects in which particular forms of time are produced, and vice versa. This does not mean that analysing timespaces is any more intuitive or straightforward than it was a decade and a half ago. Taking something as axiomatic is not always the same as being able to put it into practice in research and writing. Nor are we suggesting that advocates of the concept of timespace ever argued that the interweaving of time and space implied a fundamental equivalence between the two terms. However, it was inevitable that in trying to get round the issue of prioritizing time over space (or its inverse) differences between 'spacing' and 'timing' were downplayed or perhaps even apparently erased by the creation of a new 'thing' called timespace, which was more than just 'time plus space'. Just as there was something very analytically productive about timespace (it 
escaped from earlier dead-ends, it raised new questions), so too there has subsequently emerged something rather analytically evasive about it. Sometimes the term 'timespace' is inserted into analysis where either the term 'time' or the term 'space' might actually be more precise or clear, but where the author wants to enunciate an awareness of the dualistic error of separation. But that is just a bit slapdash and not really the point being made here. The point is that space and time might really be different, and that by trying to transcend that difference the concept of timespace allows us not to recognize or accept it.

Writing in a very different context (discussing the differences between human beings), the Cameroonian philosopher Achille Mbembe asks: 'Why is it that we believe that difference is a problem?' He also almost immediately suggests an answer: 'The moment we start making classifications, institutionalizing hierarchies in the name of difference, pretending that differences are natural and not constructed, believing that they are unchangeable and therefore legitimate, we are in trouble' (Mbembe, 2013). It is not differences that are the problem, but putting people into an order of merit on the basis of differences. Despite the fact that the object of Mbembe's discussion is so different from our own, there is a sense in which this quotation also speaks to the example of timespace: in an effort to get away from classifications and hierarchies between time and space did we forget to acknowledge the differences that were there, and also to accept that they are OK?

How might recognizing the difference between time and space turn into a practical project that also recognizes that time and space cannot be treated separately? We could perhaps use language as a metaphor here. Maybe timespace is like the idea of language in general (a unity, it unifies), but time and space are different languages (diverse singularities), or at the very least they are distinct vocabularies whose linguistic communities find their own terms to be natural, familiar, self-evident and (at least within their populations) universal. No one language is inherently 'better' than another at communicating, despite their differences. If time and space were two different languages, then the project of drawing connections across difference without erasing it would become one about translation, with all that entails in relation to searching for shared meanings, recognizing partial equivalences of meaning and sometimes accepting the untranslatability of terms too. We see the efforts made by the authors in this book to be something like translating between the vocabularies of time and space.

The reality for this specific collection of essays is that time, timing and temporalities have often been explicitly foregrounded over space, spacing and spatiality. As with the emergence of timespace, this is a reflection of 
a particular moment in a particular field. The impetus here was a dissatisfaction with the way time was being treated within the field, and there is currently an appetite to think about migration with time in mind. The project for our contributors was to theorize time in migration studies after acknowledging timespace. Having moved from time to timespace we now want to move forward again ... by going back to time.

\section{THE CHAPTERS}

Over the last few years Francis Collins and Sergei Shubin have produced a series of journal papers exploring the links between migration, temporality and subjectivity. Their chapter continues that line of enquiry, and provides a critical analysis of the standard treatment of time in the study of international student mobility, which is usually understood in terms of maximizing utility in the future by moving across a measurable grid of time and space in the present. In contrast, this chapter seeks out the complex, unexpected and ineffable experiences of temporality among young people on the move. Building their argument from Heidegger's Being and Time, they seek to move beyond linear and compartmentalized accounts of time by claiming that human being is constituted by different temporalities simultaneously. Such an examination draws out the temporal complexity whereupon age/life stage, mobility and the development of skills and competences are all seen in a broader focus and in co-existence with futures, pasts and presents of migrants. In this framing the authors highlight a discussion that moves beyond the principles of utility maximization in which students are perceived to be undertaking journeys with the goal of achieving strategic objectives. Hence, a temporal complexity can reveal the salience of subjectivity in mobility and, by extension, student migrants can be understood as undergoing processes of becoming, transformative and expressive of ambiguity which may entail anxiety and uncertainty; but, as the authors underscore, the latter need not be unproductive affects.

How does transnational family life unfold in time and space, and how does the way it unfolds matter to questions of power, agency and experience? Jørgen Carling deploys the historic distinction between space (abstract, locational) and place (humanized, meaningful) in order to break with the idea that time and space are equivalent dimensions. He argues that though time and space are inseparable aspects of transnationalism, they benefit from being treated separately so that they can then be addressed in different ways. In this way his chapter goes further than our other contributors in its critique of timespace. Using a case study of 
childhood and motherhood in transnational Cape Verdean families and a conceptual framework drawn from the time-geography of Torsten Hägerstrand, Carling argues for asserting the importance of understanding the way transnationals make meaning in particular places. This is contrasted with the way much existing analysis tends to treat transnational migration as movement over depersonalized, measurable, geometric spaces. In relation to time, he argues that the formula is almost reversed because the dominant interpretation of time in most contemporary accounts emphasizes questions of a migrant's personal embodied experiences as the route to making meaning, whereas what is less often considered are time's co-ordinates, which depend on the less voguish idea of a linear, measurable concept of time. In this way this chapter usefully challenges the consensus by arguing for the merits of thinking about time as abstract, and space (or rather place) as the site of meaning-making. Through this rethinking of timespace, mobility is re-imagined as a series of separations and unifications with people and places at key conjunctures, rather than as movement across space - an idea described as 'relative mobility'.

The working paper which initially prompted this book project by pointing to the need for migration studies to reflect more deeply on temporality was produced by Melanie Griffiths (with Ali Rogers and Bridget Anderson), so we are delighted that she has been able to 'take up the gauntlet' she threw down for herself. In her chapter Griffiths examines the changing temporal conditions, restrictions and opportunities embedded in British immigration regulations affecting 'deportable' migrants. Through this empirical lens she draws out the way that different senses of time (measurable time, linear time, monstrous time, commodified time) co-exist within the bureaucracy not as some analytical accident but for a precise political purpose, which she calls 'temporal governance'. This is the process of controlling those individuals the system has identified as ready for deportation. Immigration applications or deportation appeals are nullified by setting various complicated temporal hurdles that individuals (even those with effective lawyers) find impossible to jump. In this sense the chapter shows how a temporal analysis of topics in migration studies can not only be intellectually revealing, but can also be a framework for a normative critical account that reveals the workings of state power. In contrast to this bureaucratic and political endeavour by the state to use time to manage deportation, the chapter also draws attention to the way the human rights of those awaiting deportation are expressed in ideas of lived time. So, the expectations of privacy and access to a family life in the time remaining 
before deportation are important principles within the immigration system - albeit ones that the British government is constantly seeking to curtail because of the 'risks' they pose to efficient, speedy deportations.

At first glance international borders and regional boundaries seem to be unambiguously spatial objects. Paolo Novak, however, considers three decades of assistance for Afghan refugees over the border in Pakistan through a temporal lens, drawing attention to the changing rate of labour and refugee flows, the differentiated temporal experience of boundarycrossing and the coming-into-being of boundary lines themselves. His key concept is rhythm. The chapter assesses not only the temporal aspects of the Durand Line (the linear marker separating Afghanistan and Pakistan) but also the River Indus, which at this point forms the boundary between Islamabad and Peshawar provinces within Pakistan. Novak uses Lefebvre's idea of rhythmanalysis to provide a critical interpretation of three familiar concepts: time-space compression, border biographies and the refugee cycle regularly used in border studies. In each case this novel reading of a familiar idea reveals a diverse set of experiences of time and space. For example, while border biographies can vividly identify key moments in the life of a border, these temporal breaks need to be set against various other temporalities (of the world-system, of regional trade, of national interventions) to be understood. The concept of rhythm developed here usefully depicts the dynamic and hierarchical nature of an uneven social field by drawing attention to the multiplicity of different tempos that can be heard simultaneously - beats that are distinct but related and which, together, produce the vast unity that we seek to disentangle.

Jennifer McGarrigle and Eduardo Ascensão explore the spatial and temporal dimensions that shape migrant lived experience in the context of Lisbon, Portugal. In particular they analyse the temporary character of migration, work and movement. The chapter focuses on onward migration as a complex process of mobility encompassing the interplay between the structures of migration governance and migrant agency in terms of temporal emplacement. The analysis is grounded on two time threads following Tim Ingold's (1993) separate but intertwined divisions of time - that is, biographical/historical and everyday time. The biographical timespace of the aspirational trajectories of (predominantly) migrant men from Bangladesh, India and Pakistan contributes to creating the particularities of the conditions that play out in the everyday timespace of Lisbon in an era of economic crises. The authors' findings point to pathways of rupture and discontinuity in flow, fragmented between different places, and the entanglements of the two time threads. 
This further points to the tensions and interactions between the two threads, and hence the inherent multiplicity of timespace in migration processes.

Alex Ma's chapter examines temporality and self-development in relation to the well-being of foreign domestic workers in Singapore. The interpretation of self-development in this instance is drawn from the economist Amartya Sen's understanding of progress as an increase in an individual's capabilities. Two moments in timespace are important here: initial adjustment to life in Singapore (called 'last time') and later transitions to a position where there are some possibilities for selfdevelopment (called 'already time'). In this way temporal structures are shown to be integral to the welfare of migrants. A key element in understanding migrant welfare is clarity in obtaining knowledge of cultural and human capital. A lack of the latter can further suppress agency, and the threat of deportation can become pronounced. At the same time, the Filipino and Indonesian workers in this sample also engaged in educational classes which aided self-development and hence contributed to agency over time. All these trajectories are interlinked with the future of migrant temporalities as much as time is a core component of all the stages of their current welfare.

In what ways do some everyday experiences shape the way in which return migration is imagined? Marta Bivand Erdal answers this question by drawing on her research into transnational lives and 'return migration' between Norway and Poland/Pakistan. The analysis is framed around a strong conceptual distinction between 'imagined return' and the 'everyday experience of transnationalism', but it also sets out to show how these two registers are co-produced. In this chapter the idea of timespace becomes a tool for elucidating the different meanings of return migration for different people. Erdal draws out the profoundly different experiences for those of different generations, genders or ethnicities in order to break down the apparent unity of the idea of the imagined return. The chapter has four different empirical sections that emphasize the diversity and dynamism of return. They show: (1) how the way time is imagined in relation to return can change as a result of an individual's life experience; (2) how imagination and experience come together in the social construction of different timespaces of return; (3) how timespaces can be represented in different ways by migrants in their stories of return; and (4) how the experience of return is profoundly different for migrants' descendants when compared to the first generation. The chapter shows not only how the timespace perspective foregrounds the inherent diversity and intertwining of temporalities and spatialities in return migration, but 
also how the meanings of return are always produced in relation to experience and imagination.

The trajectories of female migrant women from the Global North who live transnational lives in Athens, Greece, are explored by Elizabeth Mavroudi through an analysis of belonging and identity. She heeds the call made by geographers concerned with non-representational theory to use the word 'space' as a verb rather than a noun. 'To space' is to participate in a world that is enacted and unfolding around oneself in a messy, hybrid mixture (between self and other, human and non-human), and which exists, for many, in the realms of creative imagination. Mavroudi argues that thinking about timespace in non-representational ways entails understanding how the interplay of time and space are negotiated in people's minds, experiences, performances and narratives. It is such an approach that this chapter argues can be useful in our analysis of migrant identities and belonging. In this framework timespace disrupts the idea(l) that there are specific ways to be and feel whilst 'on the move', and rallies against any attempts to categorize and structure belonging. Time is integral in understanding how the identities of these women are shaped and how their feelings and actions emerge in particular contexts. Such lives unfold through the timespaces of the women's experiences of whether they can really call Athens home and whether they fit in. Mavroudi examines different moments in the women's lives, and focuses on the emotional responses to specific issues. She argues that, rather than remembering the past in a linear and orderly way, timespace impacts on identity in disjointed and ambivalent ways. The chapter makes the case for adopting a non-representational lens on timespace when analysing women's identities.

Hila Zaban introduces a case study that is distinctive not only because it is empirically unfamiliar, but also because it runs against the grain of many migration stories in which people move from poorer parts of the world to richer ones. Instead she looks at the movement of affluent Jews who are leaving 'the West' (particularly France) and moving to the Jerusalem neighbourhood of Baka. Whilst Zaban acknowledges that the resources of these households mean that they appear to move freely of their own accord, she also argues that such flows are actually highly constrained - and in some ways determined by social structures in both the sending and receiving countries. For example, the role played by the organizations in Israel that support new migrants, or the legislative rules around taxation in Israel, mean that what appears to be an individual's choice is not made in a vacuum but rather in a context where certain 'choices' become far more likely than others. This dialogue between choice and constraint becomes particularly pertinent to the themes of this 
book when it illustrates how the choices of one generation become the constraints of another in Baka. So the space of the study can only possibly be understood through addressing stories of how it has changed over time: time, space, structure and agency swirl together in the production of stories about place and mobility. Thus the Arab housing stock in Baka 'abandoned' in the 1940s appeals to the first generation of incomers because it is seen as authentically Middle Eastern. It becomes ripe for gentrification by immigrants in the 1970s, and this gentrification in turn limits who can afford to move to Baka in the current day. Equally, the temporalities of immigration to Israel are shaped by Israeli military activity in the Middle East that produces a less comfortable context for Jews in the West. The moment when people move to Israel to escape hostility in Paris is produced by events in Israel itself - the chapter shows how the timing and spacing of migration is hard to separate when considered over generations.

Ben Page's chapter makes a conceptual leap from James Joyce's Ulysses to Bergson's notion of duration in order to discuss an ethnographic moment during a meal in Cameroon and, in that journey, to connect food to migrant subjectivity and self-actualization. It argues that this conceptual lens can be of value to breaking down the idea that the timespace of the migrant-subject has any essential boundary marked by an inside/outside that is contiguous with the space of the subject's body and a beginning/end that is contemporaneous with the times of the subject's 'migration'. This is an immersion into the interactive field that food studies and migration studies offer, with mnemonic, embodied and temporally constituted elements of becoming that unfold through the flow of experience. Following Bergson, the analysis explores two types of time: spatialized time (associated with the intellect) and real time (or duration), which is associated with intuition. In this context the emotional aspirations of becoming and being are captured in and through movement and the rhythms, affective energies and the forces that embodiment entails when the mundane actions of everyday life such as preparing and consuming food are disaggregated into life-journeys, migrant-journeys and journeys for research. Thus movement here becomes a vessel for subject formation, but challenges any sense of the spatial co-incidence of subject and body through these snapshots of imagined, social and research life.

Looking back at these contributions now, there are a number of points where these chapters meet (and others where they diverge too), and it is worth highlighting just a few of the themes that seem to us to emerge from these various discussions. First, some chapters make the familiar look unfamiliar by considering it through the lens of time rather than 
more familiar optics (Novak, Erdal). Second, many of the chapters suggest that an interest in time leads fairly swiftly to an interest in subjectivity and an allied suite of concepts like self, identity and belonging (Collins and Shubin, Ma, Mavroudi, Page). Looking forward there is, perhaps, a need to engage more with those authors (Hui, 2016) who have questioned the validity of treating migrants as unique and perpetually relevant subjects - thereby generating a kind of migrant exceptionalism. There is a risk that our stories of subject-formation are overdetermined in the sense that they give too much explanatory weight to the experience of migration. Third, quite a few of the chapters draw attention to questions of volition or the illusion of it (Carling, Collins and Shubin, Erdal, Griffiths, Zaban). If mobile people are constituted by different temporalities simultaneously then, as Collins and Shubin put it, 'human beings are unable to control and direct their lives along predetermined pathways'. There is a strong sense here of trying to escape from the ubiquity of the structure-agency frame, or at least of bringing some of its axioms into negotiation again. What the vocabulary of time might bring to these debates about agency is a sense of boundary-crossing creativity in the way that critical analysis addresses human potential. Fourth, a number of the chapters are seeking to move beyond utility in analysing motivations (Collins and Shubin, Ma, Page). As Ma reminds us, quoting Sheller and Urry (2006, p. 213), 'time spent traveling is not dead time that people always seek to minimise'. That is to say the journey itself is an end, not merely a means; and this must surely have a profound influence over the way we think about the relationship between movement and subjectivity.

Though the chapters of this book are philosophically profligate (unsurprising perhaps given centrality of time in philosophical enquiry and the liberality of 21st-century social science in its sources), several of them start from the premise that time-focused analysis needs to begin by moving off the idea that timespace is an inanimate grid whose co-ordinates provide locations. Instead these chapters start by engaging with the literature that emphasizes the non-linear, non-compartmentalized character of temporality (Collins and Shubin, Mavroudi, McGarrigle and Ascensão). Usefully, however, Carling provides a contrast to this dominant view by reasserting the linear qualities of time in order to explore place-making in migration journeys. There is, we suggest, an analytical restlessness that is illustrated in a reluctance to treat 'timespace' as a conceptual endpoint. 


\section{REFERENCES}

Bastia, T. and S. McGrath (2011), Temporality, Migration and Unfree Labour: Migrant Garment Workers, University of Manchester Papers in Political Economy, Working Paper no. 6.

Cheshire, J. and P. Longley (2012), 'Identifying spatial concentrations of surnames', International Journal of Geographical Information Science, 26(2), 309-325.

Collins, F. and S. Shubin (2015), 'Migrant times beyond the life course: the temporalities of foreign English teachers in South Korea', Geoforum, 62, 96-104.

Crivello, G. (2015), 'There's no future here: the time and place of children's migration aspirations in Peru', Geoforum, 62, 38-46.

Cwerner, S. (2001), 'The times of migration', Journal of Ethnic and Racial Studies, 27, 7-36.

Cwerner, S. (2004), 'Faster, faster and faster: the time politics of asylum in the UK', Time \& Society, 13, 71-88.

Gardner, K. (2009), 'Lives in motion: the life-course, movement and migration in Bangladesh', Journal of South Asian Development, 4, 229-251.

Gren, M. (2001), 'Time-geography matters', in J. May and N. Thrift (eds), TimeSpace: Geographies of Temporality, London and New York: Routledge, pp. 208-225.

Griffiths, M. (2014), 'Out of time: the temporal uncertainties of refused asylum seekers and immigration detainees', Journal of Ethnic and Migration Studies, 40(12), 1991-2012.

Griffiths, M., A. Rogers and B. Anderson (2013), Migration, Time and Temporalities: Review and Prospect, COMPAS Oxford Research Resources Paper, March.

Hui, A. (2016), 'The boundaries of interdisciplinary fields: temporalities shaping the past and future of dialogue between migration and mobilities research', Mobilities, 11(1), 66-82.

Ingold, T. (1993), 'The temporality of the landscape', World Archaeology, 25(2), $152-174$.

King, R., M. Thomson, T. Fielding and T. Warnes (2006), 'Time, generations and gender in migration and settlement', in R. Penninx, M. Berger and K. Kraal (eds), The Dynamics of International Migration and Settlement in Europe, Amsterdam: Amsterdam University Press, pp. 233-267.

Maclean, C. (2003), 'Making it their home: in-migration, time, social change and belonging in a rural community', in G. Allan and G. Jones (eds), Social Relations and the Life Course: Age Generation and Social Change, Basingstoke: Palgrave Macmillan, pp. 157-171.

Massey, D. (1994), Space, Place and Gender, Cambridge: Polity.

May, J. and N. Thift (eds) (2001), TimeSpace: Geographies of Temporality, London and New York: Routledge.

Mbembe, A. (2013), 'Why do we believe difference is a problem?', accessed 3 January 2017 at www.goethe.de/ins/br/lp/prj/eps/sob/en16082481.htm. 
McGarrigle, J. (2016), 'Islam in urban spaces: the residential incorporation and choices of Muslims in Lisbon', Journal of Ethnic and Migration Studies, 42(3), 437-457.

Peeren, E. (2006), 'Through the lens of the chronotope: suggestions for a spatio-temporal perspective on diaspora', Thamyris/Intersecting: Place, Sex and Race, 13, 67-77.

Pitt, P. (2015), 'Exploring subject positions and multiple temporalities through an Iranian migrant mother's family photograph albums', Gender, Place and Culture, 22(2), 205-221.

Potter, R. and J. Phillips (2008), 'The past is still right here in the present: second-generation Bajan-Brit transnational migrants' views on issues of race and class', Environment and Planning D: Society and Space, 26, 123-145.

Robertson, S. (2014), 'Time and temporary migration: the case of temporary graduate workers and working holiday makers in Australia', Journal of Ethnic and Migration Studies, 40(12), 1915-1933.

Robertson, S. (2016), 'Student-workers and tourist-workers as urban labour: temporalities and identities in the Australian cosmopolitan city', Journal of Ethnic and Migration Studies, 42(14), 2263-2279.

Sheller, M. and J. Urry (2006), 'The new mobilities paradigm', Environment and Planning A, 38(2), 207-226.

Shubin, S. (2015), 'Migration timespaces: a Heideggerian approach to understanding the mobile being of Eastern Europeans in Scotland', Transactions of the Institute of British Geographers, 40(3), 350-361.

Underthun, A. (2015), 'Stretching liminal spaces of work? Temporality, displacement and precariousness among transient hotel workers', in D. Jordhus-Lier and A. Underthun (eds), A Hospitable World? Organising Work and Workers in Hotels and Tourist Resorts, London and New York: Routledge, pp. 27-38.

Westin, C. (1998), 'Temporal and spatial aspects of multiculturality: reflections on the meaning of time and space in relation to the blurred boundaries of multicultural societies', in R. Bauböck and J. Rundell (eds), Blurred Boundaries: Migration, Ethnicity, Citizenship, Aldershot: Ashgate, pp. 53-84.

Wong, D. (2014), 'Time, generation and context in narratives of migrant and religious journeys', Global Networks, 14(3), 306-325. 